\title{
Short-term Consumer Benefits of Dynamic Pricing
}

\author{
Benjamin Dupont $^{\# 1}$, Cedric De Jonghe ${ }^{\# 2}$, Kris Kessels ${ }^{* 3}$, Ronnie Belmans ${ }^{\# 4}$ \\ \# Electa, Katholieke Universiteit Leuven \\ Kasteelpark Arenberg 10, 3001 Heverlee, Belgium \\ Benjamin.Dupont@esat.kuleuven.be \\ ${ }^{2}$ Cedric.DeJonghe@esat.kuleuven.be \\ ${ }^{4}$ Ronnie.Belmans@esat.kuleuven.be \\ ${ }^{*}$ VITO NV \\ Boerentang, 200, $2400 \mathrm{Mol}$, Belgium \\ Kris.Kessels@vito.be
}

\begin{abstract}
Consumer benefits of dynamic pricing depend on a variety of factors. Consumer characteristics and climatic circumstances widely differ, which forces a regional comparison. This paper presents a general overview of demand response programs and focuses on the short-term benefits of dynamic pricing for an average Flemish residential consumer. It reaches a methodology to develop a cost reflective dynamic pricing program and to estimate short-term bill savings. Participating in a dynamic pricing program saves an average consumer 2.32 percent of his initial bill. While this result seems insufficient to justify implementation, it contains only a small proportion of a series of dynamic pricing benefits.
\end{abstract}

\section{INTRODUCTION}

Historically, power markets have focused on the supplyside rather than on the demand-side. Utilities consider demand as given, assuming that a consumer is reluctant or incapable of changing its consumption pattern. Meanwhile the supply-side needs to instantaneously balance the energy system. This premise is translated into electricity pricing. Wholesale prices are highly fluctuating during the year and even within a day. Peak periods are characterized by higher generation costs, because expensive peaking plants are ramped up to cover demand. During off-peak periods, demand is typically covered by cheaper base load plants, facing must run requirements.

At the demand-side retail prices are typically kept constant for months, reflecting average generation costs during that period. Therefore, the electricity system fails to give any economic incentive to consumers to shift consumption away from peak to off-peak periods.

To resolve this shortcoming, more active involvement of the demand-side is needed. This could be accomplished by translating the real-time cost of energy directly into dynamic retail prices for consumers. This leads to a more efficient power market where peak demand is reduced, decreasing the need for expensive peak power plants and driving down the energy bills for consumers.

Although the benefits are widely known, the level of demand responsiveness in Europe is still low. A limited number of commercial and industrial consumers are provided with dynamic tariffs and the offer to residential consumers is even lower. Historically, this slow adoption has arisen from the belief of policy makers that the responsiveness of electricity consumers to dynamic tariffs is too low in comparison with the cost of implementing those tariffs [1]. As today's electricity metering and billing systems are not capable of handling dynamic tariffs, more expensive systems need to be put in place to stimulate demand response. This lack of metering and real-time billing is described as a demand-side flaw and forms one of the most critical barriers for the introduction of dynamic tariffs [2].

Fostered by the European Commission's strategy for competitive, sustainable and secure energy towards 2020 [3], demand response receives increasing attention. A European directive calls for EU member states to ensure "the implementation of intelligent metering systems that shall assist the active participation of consumers in the electricity supply markets" [4]. Subject to an economic assessment, the directive also requires $80 \%$ of all consumers to be equipped with intelligent metering systems towards 2020 . This gives a boost to demand response, because it creates a framework to tackle the demand-side flaw.

This paper examines short-term benefits for a residential consumer if he would choose to join a dynamic pricing program. Therefore it calculates the profits a consumer makes by shifting consumption according to the dynamic tariff.

To put dynamic pricing in a broader context, Section II makes distinction between several demand response programs and looks at ways to quantify demand response. The next section describes a methodology to work out a dynamic tariff and to calculate a consumer's profits. Section IV applies this methodology to the Flemish residential electricity market and compares the results with other estimations. Afterwards, Section V highlights the implementation of the dynamic tariff in the field test of the Flemish Linear project. Finally, some general conclusions are derived in the last Section.

\section{DEMAND RESPONSE: LITERATURE OVERVIEW}

Demand response is defined as a change in consumption patterns of electricity consumers in response to dynamic tariff structures or incentive payments in order to operate the electricity system in a more efficient and reliable way ([5], [6]). Two groups of demand response programs are distinguished: incentive-based and price-based demand response programs ([5], [6]). Within each program, several subcategories exist. An overview is provided in Fig. 1. 


\begin{tabular}{|c|c|c|c|c|c|}
\hline \multicolumn{6}{|c|}{ Demand response } \\
\hline \multicolumn{3}{|c|}{ Incentive-based } & \multicolumn{3}{|c|}{ Price-based } \\
\hline $\begin{array}{c}\text { Direct load } \\
\text { control } \\
\text { programs }\end{array}$ & $\begin{array}{c}\text { Curtailable } \\
\text { load } \\
\text { programs }\end{array}$ & $\begin{array}{l}\text { Demand } \\
\text { bidding } \\
\text { programs }\end{array}$ & \multirow{2}{*}{$\begin{array}{l}\text { Time-of- } \\
\text { use pricing }\end{array}$} & \multirow{2}{*}{$\begin{array}{c}\text { Critical } \\
\text { peak } \\
\text { pricing }\end{array}$} & \multirow{2}{*}{$\begin{array}{c}\text { Real-time } \\
\text { pricing }\end{array}$} \\
\hline $\begin{array}{c}\text { Emergency } \\
\text { demand } \\
\text { response } \\
\text { programs }\end{array}$ & $\begin{array}{c}\text { Capacity } \\
\text { market } \\
\text { programs }\end{array}$ & $\begin{array}{l}\text { Ancillary } \\
\text { services } \\
\text { market } \\
\text { programs }\end{array}$ & & & \\
\hline
\end{tabular}

Fig. 1. Demand response programs

At the left hand side of Fig. 1, incentive-based programs are depicted. In those programs, participating customers receive payments for reducing their loads at critical times. Incentive-based programs include six subcategories: direct load control, curtailable load, demand bidding, emergency demand response, capacity market and ancillary services markets programs. In direct load control programs, a third party is in control of some appliances at the consumer's premises (e.g. air conditioners, heat pumps). In the event of system disruptions, the third party can control those appliances directly in compensation for a previously known participation fee. In curtailable load programs [7] the consumer is in control of his own appliances. By enrolling into the program, the consumer makes the commitment to modify his load when he receives a request. The gain for the participants can take different forms: lower electricity prices, bill credits, participation fees, etc. A penalty is accounted for, if the customer does not respond to the load signal. In demand bidding programs a consumer makes the engagement to modify his load by bidding in the wholesale electricity market. If the bid is called, the consumer is obliged to reduce his load to the according level. Emergency demand response programs are called upon times when system security is in danger. Consumers get incentive payments for helping to resolve system stability during security events. Capacity market programs make use of load reduction commitments [7]. These commitments partly replace traditional generation commitments on capacity reserve markets. Participating consumers receive an up-front payment for offering the load capacity, added with a payment for calling the capacity in case of an event. In ancillary market programs consumers bid load reduction commitments in the spot markets as operating reserves [8]. When the bid is accepted, consumers receive an up-front payment which reflects the spot market price for being on stand-by. Once the load reduction is called for, consumers receive the additional spot market electricity price.

Price-based demand response programs are depicted at the right hand side of Fig. 1. In those programs, time-varying tariff structures reflect the actual cost of energy. Those structures are offered to make consumers shift consumption from high price periods to low price periods. Although a lot of variants of price-based demand response programs exist, most can be classified within three subcategories: time-of-use pricing, critical peak pricing and real-time pricing [9]. While all three are characterized by time-varying tariff structures which reflect the underlying cost of energy, the frequency of updating predetermined prices differs. Time-of-use tariffs divide the day into different time blocks to which different electricity prices apply. These prices are fixed for a specific period (e.g. a month). Even though they reflect the average cost of energy during the time blocks, they fail to account for short-term variability in wholesale prices. This is partly resolved by critical peak pricing, which adds a critical peak component to time-of-use or flat tariffs. This additional component is only applied during critical peak hours for a limited number of hours a year. Typically the consumer receives the critical peak tariffs on short notice. As a refund, a price discount during non-critical peak hours applies. The variability of the electricity tariff is even greater with realtime prices, which typically reflect hourly wholesale prices. Between a day-ahead and an hour-ahead, the consumer receives new hourly electricity prices. This pricing program allows reflecting the underlying cost of energy at all times.

The main difference between incentive-based and pricebased demand response programs is the level of consumer involvement in load modification. Incentive-based programs trigger load modification in the occasion of critical events based on contractual arrangements. Although participation is voluntary, falling short on a specific demand response request brings about penalties. In price-based programs, the consumer enrolls in a dynamic pricing scheme. Voluntary load modifications are based on the customer's own economic and rational preferences. While incentive-based programs are mostly performed on large industrial customers, price-based programs cover a variety of customer groups. Studies found that price responsiveness is considerably lower for small and medium commercial and industrial customers than for residential customers [10].

Demand response induced by dynamic pricing brings about several benefits for the participants and the society as a whole ([5], [6]). An overview is depicted in Fig. 2.

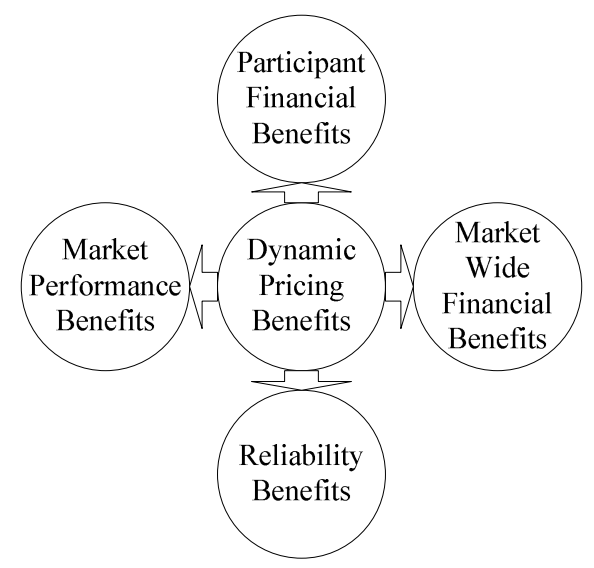

Fig. 2. Dynamic pricing benefits

The benefits can be split up in four categories: participant financial benefits, market wide financial benefits, reliability benefits and market performance benefits. First of all, participants financial benefits consist of short-term direct bill savings from reducing consumption during expensive peak periods. Second, market wide financial benefits are divided 
into short-term and long-term benefits. In the short run, reducing consumption in expensive peak periods leads to a reduced start-up of expensive peaking units. This causes lower wholesale prices during peak periods. In the long run, utilities avoid capacity, transmission and distribution costs [11], because the system can be tuned on a lower peak demand due to sustained demand response. These benefits result in a lower electricity price for both participating and non-participating consumers. Third, demand response leads to reliability benefits [12], because additional system flexibility reduces the probability of forced outages [13]. Finally, dynamic pricing can lead to market performance benefits [14]. Consumer's ability to decrease electricity consumption during high price moments, reduces generator's incentive to bid above marginal generation costs. The resulting reduced market power abuse is considered to be a significant benefit.

To quantify these benefits, the level of demand response induced by dynamic pricing needs to be known. This can be expressed in two ways. At first, demand response is measured as a peak demand reduction. Generally, this parameter gives the percentage the demand has dropped during peak periods. Although this gives an indication of the peak reduction potential, no information is given on the aggregated load modification. The second way of expressing demand response, is by price elasticity. Price elasticity represents the responsiveness of consumer demand to electricity price changes [15]. Hereby, a distinction is made between ownprice elasticity and substitution elasticity of electricity demand. Own-price elasticity typically captures transformation behavior of electricity consumers. This transformation represents an adjustment in the overall level of electricity consumption due to a change in electricity prices relative to other goods and services. This is contrary to shifting behavior of electricity consumers [16]. Here, the overall level of consumption remains equal, but due to price differences the electricity consumption is shifted to other price periods. This shifting behavior is expressed by the substitution elasticity of electricity demand.

\section{METHODOLOGY}

This section describes a methodology to estimate shortterm benefits of demand response for residential consumers. As described above, there exists a wide variety of demand response programs. These can bring several benefits to consumers and society. This paper focuses on the benefits for a consumer if he decides to participate in a price-based demand response program that communicates dynamic prices on a day-ahead basis. The analysis only covers the accrued short-term benefits by shifting behavior and neglects transformation behavior. The benefits are inspired by a general peak load reduction estimate.

The flowchart of the methodology to estimate the shortterm benefits can be found in Fig. 3. In the following subsections, each step is clarified.

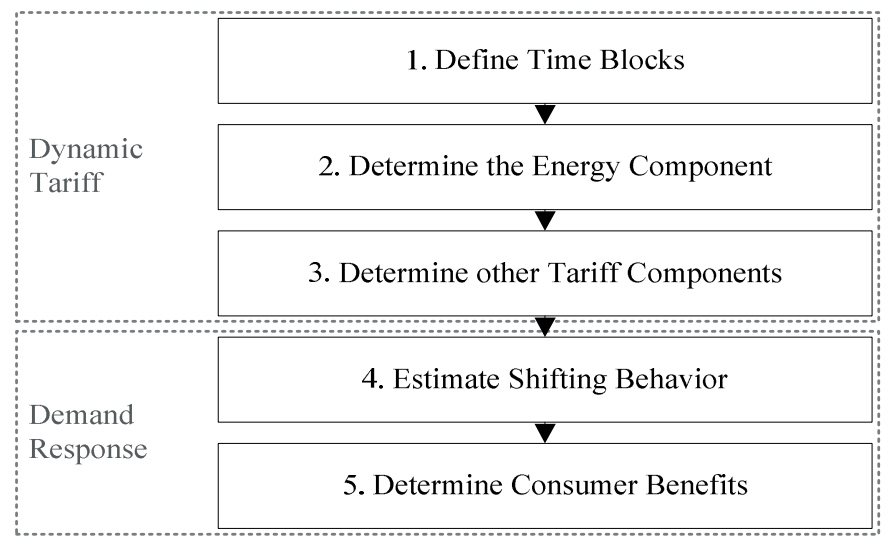

Fig. 3. Methodology to estimate short-term benefits

\section{A. Dynamic Tariff}

At first, a new dynamic tariff is developed (steps $1-3$ ). This paper develops a dynamic tariff with fixed time blocks in which a variable day-ahead price is applicable. Each day is divided in six or seven fixed time blocks, according to the season of the year. Each time block reflects the underlying cost of energy.

Well-designed tariffs have to meet some requirements to be accepted by electricity consumers and to bring about a high level of load modification. A distinction between six vital requirements is made: simplicity, short peak periods, strong price signals, opportunity of significant bill savings, reflection of system costs and revenue neutrality [17]. In the following parts, all requirements are taken into account when designing the dynamic tariff.

1) Time blocks: Forthcoming the simplicity requirement, each day is divided into a limited number of time blocks to which different electricity prices apply. Because the intraday variability of underlying prices highly depends on the day of the year, a distinction is made between week and weekend days on the one hand, and winter/autumn and summer/spring days on the other hand. For each of the four typical days, different time blocks are defined. An example is given in Table I. To cope with the requirements of [17], the time block which covers the peak is chosen as short as possible. This makes it easier for participants to avoid the peak period. This also gives a stronger pricing signal to the consumer, because it captures only the peak period. If the peak period would last longer, the peak price is flattened by averaging with shoulder periods. This would lead to a lower opportunity for bill savings.

TABLE I

TIME BLOCKS

\begin{tabular}{l|l}
\hline Typical Days & Time Blocks \\
\hline Winter/autumn week day & $0-7-9-12-17-20-24$ \\
\hline Winter/autumn weekend day & $0-7-10-13-18-21-24$ \\
\hline Summer/spring week day & $0-7-10-13-17-20-23-24$ \\
\hline Summer/spring weekend day & $0-7-10-13-18-21-23-24$ \\
\hline
\end{tabular}


2) Energy component: Residential electricity prices consist of four components: energy, transmission, distribution and levies. While the last three components remain fixed in this methodology, the energy component is made variable. To incorporate this variability, hourly day-ahead wholesale prices $^{1}$ are used. Although in practice residential tariffs can be constructed differently, this methodology convenes with the requirement that a well-designed tariff reflects system costs. The wholesale prices are translated into the energy component of the electricity price by multiplying with a rescaling factor. This factor is based on the principle of revenue neutrality. If an average consumer does not change its consumption pattern, the yearly electricity bill would be the same under the dynamic tariff and under the initial electricity tariff. To obtain a valid rescaling factor, the average wholesale electricity price and consumption level per time block are needed. Wholesale prices are calculated by averaging hourly wholesale prices for each time block. Consumption levels per time block are estimated by average load profiles ${ }^{2}$, which specify the consumption on a quarter hour basis.

After having set the electricity price and consumption level for each time block, the rescaling factor is calculated using the following formula:

$\sum_{i}\left[\sum_{j}\left[C L_{i j} \times W P_{i j}\right] \times X\right]=A E T C$

With:

$C L_{i j}$ : $\quad$ Consumption level during a typical day $i$ and time block $j[\%$ of total consumption]

$W P_{i j}$ : Wholesale price during a typical day $i$ and time block $j[€ / \mathrm{MWh}]$

$X$ : Rescaling Factor

AETC: Average energy tariff component over the year $[€ / \mathrm{MWh}]$

Once the rescaling factor is determined, the daily energy component is calculated. As an example, Fig. 4 and Fig. 5 depict the energy component of the dynamic tariff for a typical winter/autumn weekday and a typical summer/spring weekday.

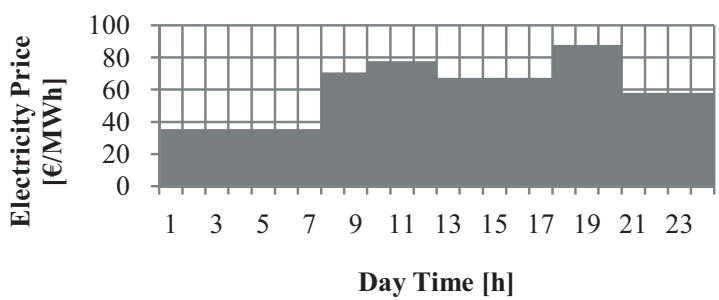

Fig. 4. Energy component price for a typical winter/autumn weekday

\footnotetext{
1 This paper uses market data from The Belgian Power Exchange (BELPEX). Available: http://www.belpex.be

${ }^{2}$ This paper uses a residential Synthetic Load Profile from the Belgian federation of system operators for electricity and gas (SYNERGRID). Available: http://www.synergrid.be
}

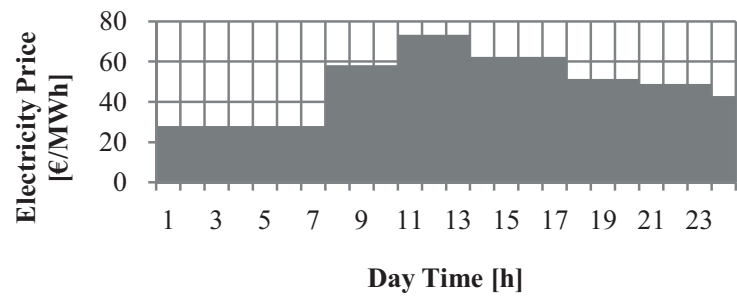

Fig. 5. Energy component price for a typical summer/spring weekday

3) Other tariff components: The fixed transmission, distribution and levy components are added to the energy component. This leads to the complete electricity tariff which can be communicated to the consumers.

\section{B. Demand Responsiveness}

Once the full dynamic tariff is known, a demand response estimate determines the short-term consumer benefits from joining the dynamic pricing program. To calculate this, an understanding of the shifting behavior of a residential consumer is needed (steps $4-5$ ).

1) Estimate shifting behavior: Shifting behavior of consumers differs according to the quantity of load shifting and the time frame to which the load is shifted. First, an indication on the level of peak load reduction is needed (e.g. ten percent of the peak load is shifted to other time frames). Afterwards, the time frame to which the load is shifted has to be determined (e.g. load shift from the peak period to the lowest price period).

2) Determine consumer benefits: Once the shifting behavior is estimated, consumer benefits can be calculated using the following formula:

$\sum_{i}\left[T C_{i} \times P R \times P D_{i}\right]=T B R$

With:

$T C_{i}$ : $\quad$ Total consumption during a typical day $i$ [MWh]

$P R: \quad$ Peak reduction [\% of total consumption]

$P D_{i}$ : $\quad$ Price difference between peak and off-peak period during a typical day $i[€ / \mathrm{MWh}]$

TBR: Total bill reduction at the end of the year [€].

\section{DEMAND RESPONSE IN FLANDERS}

\section{A. Flemish Input Data}

The developed methodology is applied to Flemish residential consumers. Therefore, estimates on electricity consumption, electricity prices, tariff components and demand responsiveness are needed. Table II represents the different parameters. 
TABLE II

SCENARIOS

\begin{tabular}{l|l|l|l}
\hline Scenario & Low-level & Baseline & High-level \\
\hline $\begin{array}{l}\text { Residential Electricity } \\
\text { Consumption [MWh] }\end{array}$ & 3.50 & 4.40 & 7.50 \\
\hline $\begin{array}{l}\text { Electricity Price } \\
\text { [€/MWh] }\end{array}$ & 150.00 & 171.00 & 192.00 \\
\hline $\begin{array}{l}\text { Energy Component } \\
\text { [€/MWh] }\end{array}$ & 84.00 & 95.76 & 107.52 \\
\hline $\begin{array}{l}\text { Other Components } \\
{[€ / \mathrm{MWh}]}\end{array}$ & 66.00 & 75.24 & 85.52 \\
\hline $\begin{array}{l}\text { Demand Response [\% } \\
\text { of total consumption] }\end{array}$ & 2 & 10 & 20 \\
\hline Shifting Behavior & $\begin{array}{l}\text { from } \\
\text { average to } \\
\text { low price } \\
\text { periods }\end{array}$ & $\begin{array}{l}\text { from high } \\
\text { to average } \\
\text { price } \\
\text { periods }\end{array}$ & $\begin{array}{l}\text { from high } \\
\text { to low } \\
\text { price } \\
\text { periods }\end{array}$ \\
\hline
\end{tabular}

To quantify the impact of the different parameters a distinction is made between three scenarios (low-level, baseline and high-level). In the baseline scenario parameters take up the most up-to-date values. The low- and high-level scenario correspond to parameter values which respectively decrease and increase the short-term consumer benefits of shifting.

Data concerning the electricity consumption and price are based on a report from the Flemish Energy Regulator [18]. This report states that the average consumption of a Flemish residential consumer amounts to $4.4 \mathrm{MWh}$ a year. The lowlevel and high-level values correspond respectively to a consumption level of 3.5 and 7.5 MWh a year. The electricity price for residential consumers in Flanders amounts on average to 171 euro/MWh of which 56 percent is attributable to the energy component. The rest is captured by the transmission, distribution and levy component. While the distribution among components is kept at the same percentage of the electricity price, the electricity price itself is adjusted for the low-level and high-level scenario.

Data concerning the level of demand response are inspired by European and American experiences. The Brattle Group estimates the average European peak load reduction due to dynamic pricing between 8 and 10 percent [19]. The Federal Energy Regulatory Commission (FERC) bundled pilot projects from all over the United States and concluded that peak load reduction ranged from under 5 up to 50 percent [20]. This illustrated the geographical variation in the amount of demand response. As the demand response level largely varies with tariff type, climate zone, season, air conditioning ownership and other consumer characteristics [21], Flemish shifting potential is estimated at 2, 10 and 20 percent of total consumption. The baseline shifting behavior of residential consumers is approximated by a shift from high to average price periods. The low level scenario represents a shift from average to low price periods. The high level scenario corresponds to a shift from a high to a low price period. This calls for the highest flexibility of appliances.

\section{B. Results and scenario analysis}

Following the integration of Flemish data in the methodology from the previous section, an average customer attains a direct short-term electricity bill reduction of 17.52 euro in the baseline scenario. Although this represents only a small fraction $(2.32 \%)$ of the initial bill, other benefits which are not covered in this analysis will add up to this.

Because a lot of these data are covered with uncertainty, Table III depicts a scenario analysis to represent the influence of the input data on the results.

\section{TABLE III}

SCENARIO ANALYSIS

\begin{tabular}{l|l|l|l}
\hline Bill Savings & Low-level & Baseline & High-level \\
\hline Residential Electricity & $€ 13.94$ & $€ 17.52$ & $€ 29.87$ \\
Consumption & $(2.32 \%)$ & $(2.32 \%)$ & $(2.32 \%)$ \\
\hline Electricity Price & $€ 15.37$ & $€ 17.52$ & $€ 19.78$ \\
& $(2.04 \%)$ & $(2.32 \%)$ & $(2.63 \%)$ \\
\hline Demand Response & $€ 3.50$ & $€ 17.52$ & $€ 35.05$ \\
& $(0.47 \%)$ & $(2.32 \%)$ & $(4.66 \%)$ \\
\hline Shifting Behavior & $€ 15.36$ & $€ 17.52$ & $€ 32.80$ \\
& $(2.04 \%)$ & $(2.32 \%)$ & $(4.36 \%)$ \\
\hline
\end{tabular}

Table III illustrates that bill savings largely depend on data input. If the same analysis is done for a residential consumer with an electricity consumption of 7.5 MWh, benefits run up to almost 30 euro. Because this includes the same demand responsiveness, the bill savings remain equal in percentage. The largest spread of results can be found for the demand response parameter. Low-level demand response results in an electricity bill saving of 3.50 euro. This represents only 0.47 percent of the initial bill. A high-level demand response saves 35.05 euro, representing 4.66 percent of the initial electricity bill. This is in line with the high-level shifting behavior scenario, which brings about a bill saving of 32.80 euro.

\section{Regional comparison}

A comparison with results from other regions elaborates this picture. In [22], the average residential bill savings from switching to a real-time electricity price are estimated at 5.9 percent of the initial electricity bill. This captures demand responsiveness in Californian households, which are characterized by a high level of air conditioning implementation. Furthermore, these results entail the substitution elasticity and the own price elasticity of demand, explaining the considerably higher level of bill savings.

Borenstein [23] states that customer demand savings range from 2.0 to 13.7 percent depending on the responsiveness of demand. As the analysis captures the long-term benefits of real-time pricing of Californian Households, the bill savings largely exceed the results from this paper.

\section{FIELD TEST}

As the level of demand responsiveness varies around the globe, the Linear project ${ }^{3}$ sets up a field test [24]. This field test tries to reveal the potential of demand response by communicating dynamic prices to residential consumers in

\footnotetext{
3 (2011) The Linear website. Available: http://www.linear-smartgrid.be/
} 
Flanders. The prices are sent on a day-ahead basis taking into account the variability in wholesale prices and adding an extra component for wind and solar energy. This extra component reflects the higher variability of electricity prices, if more intermittent renewable energy is integrated into the power system. The results of the field test will reveal price elasticities for Flemish residential consumers. This allows determining short-term and long-term consumer and system benefits of dynamic pricing in Flanders.

\section{CONCLUSION}

This paper gives a general overview of demand response and estimates the influence of dynamic pricing on the electricity bill of a residential consumer. A distinction is made between incentive-based and price-based demand response programs. Within price-based programs, dynamic tariffs such as time-of-use, critical peak and real-time pricing are included. These bring benefits to participants and society as a whole.

This paper focuses on the short-term residential bill savings from stepping in a dynamic pricing program. To estimate these savings, a methodology is provided. This methodology constructs a dynamic tariff facing the requirements of a welldesigned tariff. Afterwards, demand response characteristics are added to estimate the bill savings. To get an overall picture of the profitability of the implementation of dynamic pricing, other benefits need to be calculated.

Applied to Flanders, the yearly benefits amount to 17.52 euro, representing 2.32 percent of the initial electricity bill. A scenario analysis is performed to put the results into perspective. The analysis illustrates that results largely depend on data input concerning the level of demand response. Results range from a yearly bill saving of 0.47 percent stemming from a low level of demand response to 4.66 percent stemming from a high level of demand response. Also shifting behavior affects bill savings significantly. If a consumer can shift his flexible load from the highest to the lowest price period, bill savings count to 4.36 percent.

To get a detailed picture of consumer reactions to dynamic prices, the Linear project sets up a pilot project to test demand response in Flanders. Using these results, general short-term and long-term benefits can be estimated. This gives a tool to evaluate whether an overall introduction of dynamic pricing entails enough benefits to exceed implementation barriers.

\section{ACKNOWLEDGMENT}

This work is supported by the Flemish Ministry of Science (Minister I. Lieten) via the project Linear organized by the Institute for Science and Technology (IWT).

\section{REFERENCES}

[1] J. Torriti, M. G. Hassan, and M. Leach. "Demand Response Experience in Europe: Policies, Programs, and Implementation", Energy, Volume 35, Issue 4, Pp. 1575-1583, April 2010.

[2] S. Stoft, Power System Economics: Designing Markets for Electricity, New York: Wiley-IEEE Press, 2002.

[3] European Commission, "Energy 2020: A Strategy for Competitive, Sustainable and Secure Energy", SEC(2010) 1346, Brussels, 2010.

[4] European Parliament, "Directive 2009/72/EC of the European Parliament and of the Council of 13 July 2009 concerning Common
Rules for the Internal Market in Electricity and Repealing Directive 2003/54/EC", OJ 2009 211/55, 2009.

[5] Department of Energy, "Benefits of Demand Response and Recommendations", a Report to the United States Congress Pursuant to Section 1252 of the Energy Policy Act of 2005, United States, February 2006.

[6] M.H. Albadi, and E.F. El-Saadany, "A Summary of Demand Response in Electricity Markets", Electric Power System Research, Vol. 78, Pp.1989-1996, Nov. 2008.

[7] H.A. Aalami, M. Parsa Moghaddam, and G.R. Yousefi, "Demand Response Modeling Considering Interruptible/Curtailable Loads and Capacity Market Programs", Applied Energy, Vol. 87, Issue 1, Pp. 243250, Jan. 2010.

[8] B. Kirby, "Spinning Reserve from Responsive Load", Oak Ridge National Laboratory, ORNL/TM2003/19, Jan. 2003.

[9] S. Borenstein, M. Jaske, and A. Rosenfeld, "Dynamic Pricing, Advanced Metering and Demand Response in Electricity Markets", The Energy Foundation, CSEM WP 105, Oct. 2002.

[10] A. Faruqui, and S. George, "The Value of Dynamic Pricing in Mass Markets", The Electricity Journal, Vol. 16, Issue 6, Pp. 45-55, July 2002

[11] G. Strbac, "Demand Side Management: Benefits and Challenges", Energy Policy, Vol. 36, Issue 12, Pp. 4419-4426, Dec. 2008.

[12] J.D. Kueck, B.J. Kirby, J.H. Eto, R.H. Staunton, C. Marnay, C.A. Martinez, and C. Goldman, "Load as a Reliability Resource in Restructured Electricity Markets", Oak Ridge National Laboratory, ORNL/TM2001/97, LBNL-47983, June 2001.

[13] M.C. Caramanis, R.E. Bohn, and F.C. Schweppe, "Optimal Spot Pricing: Practice and Theory",, IEEE Transactions on Power Apparatus and Systems, Vol. PAS-101, Issue 9, Pp. 3234-3245, 1982.

[14] K. Spees, and L. B. Lave, "Demand Response and Electricity Market Efficiency", The Electricity Journal, Vol. 20, Issue 3, pp. 69-85, April 2007.

[15] B. Neenan and J. Eom, "Price Elasticity of Demand for Electricity: A Primer and Synthesis", Electric Power Research Institute, Jan. 2008.

[16] C. W. Gellings, "The Concept of Demand-Side Management for Electric Utilities" Proceedings of the IEEE, Vol. 73, Issue. 10, pp. 1468-1470, June 1985.

[17] A. Faruqui, R. Hledik, and S. Sergici, "Piloting the Smart Grid", The Electricity Journal, Vol. 22, Issue 7, Aug./Sept. 2009.

[18] Vlaamse Reguleringsinstantie voor de Elektriciteits- en Gasmarkt, "Marktmonitor 2010", VREG, 2010. [Online]. Available: http:/www.vreg.be/

[19] A. Faruqui, D. Harris, and R. Hledik, "Unlocking the $€ 50$ Billion Savings from EU Smart Meters, how increasing the adoption of dynamic tariffs could make or break the EU's smart grid investment", The Brattle Group, Oct. 2009.

[20] FERC Staff, "A National Assessment of Demand Response Potential", The Brattle Group, Freeman, Sullivan \& Co., and Global Energy Partners, June 2009

[21] A. Faruqui, and S. George, "Quantifying Customer Response to Dynamic Pricing”, The Electricity Journal, Vol. 18, Issue 4, Pp. 53-63, May 2005.

[22] A. Faruqui, R. Hledik, and J. Tsoukalis, "The Power of Dynamic Pricing", The Electricity Journal, Vol. 22, Issue 3, Pp. 42-56, April 2009

[23] S. Borenstein, "The Long Run Efficiency of Real-Time Electricity Pricing", Energy Journal, 26, 3. at 93, 2005.

[24] E. Peeters, C. Develder, J. Das, J. Driesen, and R. Belmans, "Linear: Towards a Breakthrough of Smart Grids in Flanders", i-SUP conference, paper 230, Bruges, April, 2010. 